\title{
Clinico-pathological features of bladder carcinoma in women in Pakistan and smokeless tobacco as a possible risk factor Muhammad Rafique*
}

\author{
Address: Department of Urology, Nishtar Medical College, Multan, Pakistan \\ Email: Muhammad Rafique* - rafiqanju@ hotmail.com \\ * Corresponding author
}

Published: 05 August 2005

World Journal of Surgical Oncology 2005, 3:53 doi:10.1 186/1477-7819-3-

53

This article is available from: http://www.wjso.com/content/3/l/53

(c) 2005 Rafique; licensee BioMed Central Ltd.

This is an Open Access article distributed under the terms of the Creative Commons Attribution License (http://creativecommons.org/licenses/by/2.0), which permits unrestricted use, distribution, and reproduction in any medium, provided the original work is properly cited.
Received: 12 April 2005

Accepted: 05 August 2005

\begin{abstract}
Background: Bladder carcinoma is one of the common urological malignancies occurring worldwide in both sexes. Use of smokeless tobacco by women is common in rural areas of Pakistan. The clinico-pathological features of bladder carcinoma in women and association of smokeless tobacco as a possible risk factor for bladder carcinoma has not been well described in the literature. The objective of the study was to determine the clinico-pathological features of histologically confirmed bladder carcinoma in women and to investigate the role of smokeless tobacco use as a possible risk factor for its development.
\end{abstract}

Patients and methods: Of the 204 patients (I60 male and 44 female M:F ratio 3.6:I) of newly diagnosed bladder carcinoma treated at Nishtar Medical College Hospital Multan from January 1998 to December 2004, the 44 female patients were evaluated with respect to age, clinical presentation, cystoscopic findings, histopathological reports and possible etiological factors. Data were collected and prospectively updated at the time of discharge from hospital and during followup in urology out-patient clinic.

Results: Transitional cell carcinoma accounted for all of the bladder carcinoma in women. Median age of the patients was 55 years and $68 \%$ patients were under 60 years of age. Majority of patients (88\%) presented with hematuria. Eleven (25\%) patients had superficial (pTa/pTI) while $33(75 \%)$ patients had muscle invasive (T2-T4) bladder carcinoma. Most (81\%) superficial tumors were papillary while muscle invasive tumors had solid configuration at cystoscopy. Of these, 21 (47\%) patients had long history of smokeless tobacco use (chewable or moist snuff).

Conclusion: Transitional cell carcinoma is the most common bladder malignancy in women in Pakistan. Many women with bladder carcinoma had long history of use of smokeless tobacco. Majority of patients presented with hematuria and were under 60 years of age. At the time of diagnosis $75 \%$ women had muscle invasive bladder carcinoma. In women using smokeless tobacco, the correlation between stage of bladder carcinoma and duration of smokeless tobacco use was significant $(p=0.03)$. Further studies are needed to clarify the role of smokeless tobacco in the development of bladder carcinoma. 


\section{Background}

Bladder carcinoma is one of the most common malignancies occurring worldwide. It is seen mainly in men. The incidence in women is approximately 3 to 4 times lower than in men but it seems to be rising [1]. Bladder cancer has been associated pathogenetically with many etiological factors which include occupational exposure to certain chemicals e.g. aniline dyes, cigarette smoking, viral agents, bacterial and parasitic infections, cystolithiasis, cyclophosphamide therapy and pelvic irradiation [2].

The initial clinical evaluation consists of history and physical examination, upper tract studies (IVU +/- Ultrasonography) and urine cytology followed by cystoscopy and transurethral resection of bladder tumor.

Most cases of the bladder carcinoma are superficial at the time of diagnosis (stage Ta-T1). The recurrence of the superficial tumors can be as high as $70 \%$, with $10-15 \%$ progressing to muscle invasive disease [3].

Despite the fact that bladder carcinoma is among one of the common malignancies in women worldwide, the etiological and clinico-pathological aspects of bladder carcinoma are not well described in the literature. In contrast to many Western countries use of smokeless tobacco in women is quite common in rural areas of Pakistan. The primary objective of the present study was to determine the clinico-pathological features of histologically confirmed bladder carcinoma in women and the secondary objective was to investigate smokeless tobacco use as a possible risk factor for it.

\section{Patients and methods}

Two hundreds and four patients of newly diagnosed bladder carcinoma were treated in the department of urology, Nishtar Hospital Multan, Pakistan from Jan 1998 to December 2004. Age, clinical presentation, cystoscopic findings and histopathological reports, and possible etiological risk factors of bladder carcinoma in women were studied prospectively.

After initial clinical evaluation and routine hematological, biochemical and radiological investigations all patients underwent cystoscopy and transurethral resection of bladder tumor (TURBT). All women were treated as inpatients and none of the patients had undergone TURBT previously. In all cases complete removal of papillary tumor was performed. In cases of solid muscle invasive tumors either complete resection or generous debulking of exophytic tumor was carried out. Cystoscopic tumor configuration was compared with the histopathological reports. Data were collected and prospectively updated at the time of discharge from hospital and during follow-up in urology out-patient clinic.
Detailed information about the smoking habits, use of smokeless tobacco (chewable or snuff), use of hair coloring dyes, occupational exposure to chemicals was obtained from all patient. Many of the women had long history of smokeless tobacco use, its duration and frequency was inquired from such patients. Possible effect of smokeless tobacco on the depth ( $\mathrm{T}$ category) of bladder carcinoma in such patients was studied and compared with patients not using any form of tobacco.

\section{Results}

Two hundred and four patients (160 male and 44 female with male female ratio 3.6:1) were treated. The age of the female patients ranged from 26-80 years (median age 55 years). Hematuria was the predominant symptom in 39 (88.6\%) patients at the time of presentation. A total of 21 patients had painless and 18 patients had painful hematuria. Four patients presented with various urinary complaints but had no hematuria. In one patient the bladder tumor was incidentally detected on ultrasonography performed for some other complaints. The mean duration of symptoms was 4 months (range 2 weeks to 16 years)

At presentation mean hemoglobin concentration was 9.5 grams/dL (range 3.9 grams to 13.3 grams). Six (13.6\%) patients had renal insufficiency (serum creatinine $>1.5$ $\mathrm{mg} \%$ ) secondary to ureteric obstruction from bladder carcinoma. All patients had transitional cell carcinoma. Eleven (25\%) patients had non-invasive superficial (i.e. pTa or pT1) transitional cell carcinoma while 33 (75\%) patients had muscle invasive (T2-T4) transitional cell carcinoma. The median duration of symptoms for noninvasive transitional cell carcinoma was 1.5 years (range 2 weeks to 16 years) and it was 4 months (range 1 month to 2 years) for muscle invasive carcinoma.

Most superficial tumors had papillary and muscle invasive tumors had solid configuration at cystoscopy. Average size of the superficial and invasive tumor was $4 \mathrm{~cm}$ (range 1$8 \mathrm{~cm}$ ) and $3.8 \mathrm{~cm}$ (range $2-8 \mathrm{~cm}$ ) respectively. Of the superficial tumors $2(18 \%)$ were pTa and $9(82 \%)$ were pT1 tumors. Three pT1 tumors were grade I and five patients had grade II tumors. One patient had high-grade pT1 grade III carcinoma. There was no carcinoma in situ although no random biopsies were taken.

Of the muscle invasive tumors $\mathrm{T} 2, \mathrm{~T} 3$ and $\mathrm{T} 4$ tumors were present in 14, 15 and 4 patients respectively. Thirteen patients with muscle invasive disease had histological grade III carcinoma while twenty patients had grade II carcinoma. None of the patients had GI tumor. Two patients had marked iliac and para-aortic lymphadenopathy while one patient had iliac and para-aortic lymphadenopathy and liver metastases at the time of diagnosis. 
Table I: Depth (T category) of bladder carcinoma and duration of smokeless tobacco use

\begin{tabular}{|c|c|c|c|c|c|}
\hline & \multicolumn{5}{|c|}{ Duration of smokeless tobacco use } \\
\hline & $1-10$ years & I I-20 years & $21-30$ years & $31-40$ years & Total \\
\hline TI (pTa/pTI) & I & 2 & I & & 4 \\
\hline T2 & & 3 & 3 & & 6 \\
\hline T3 & & 2 & 6 & 1 & 9 \\
\hline T4 & & & 2 & & 2 \\
\hline Total & 1 & 7 & 12 & 1 & 21 \\
\hline
\end{tabular}

All females were non smokers but 21 (47\%) patients had long history of smokeless tobacco use (moist snuff (niswar) 12 patients, chewable tobacco (beera) in 5 patients and chewed tobacco with betel nuts (pan) in 4 patients most of these were currently using these substances at the time of presentation. All such patients came from rural areas of Punjab and were uneducated. Patients were asked whether they were using smokeless tobacco 5 or less than 5 times/day or greater than 5 times /day.

By employing cross tabulation (table 1) of duration of smokeless tobacco use and depth (T category) of bladder carcinoma, it appears that majority of such patients had muscle invasive carcinoma at presentation and about $60 \%$ of patients have been using smokeless tobacco between 20-30 years. The correlation between the depth of bladder carcinoma and duration of smokeless tobacco use was 0.473 which is statistically significant $(p=0.03)$. However correlation between bladder carcinoma and intensity of exposure to smokeless tobacco was 0.24 which showed a weak relationship. This might be due to the fact that the patients were using different quantities of smokeless tobacco from different sources.

We applied two independent sample $t$ test for the comparison of depth of invasion. (by using T category of TNM stage) of bladder carcinoma in users and nonusers of smokeless tobacco. Patients using smokeless tobacco were assigned to group I and nonusers to group II (i.e. control group). The mean depth of bladder carcinoma in group I and II was 2.43 (standard deviation 0.93 ) and 2.13 (standard deviation 0.97 ) respectively. The datum shows that the carcinoma are of higher depth (T category) in group I, however the $t$ value for the difference between the two groups is 1.04 which indicated that this difference was not statistically significant. Larger studies should be able to clarify the role of smokeless tobacco as an etiological risk-factor for bladder carcinoma.

\section{Discussion}

Bladder carcinoma is the fourth most common cancer in men in the USA and eight most common cancers in women [4]. In Pakistan bladder carcinoma is one of the top ten malignancies in men and most common urological malignancy in both sexes [5]. Bladder cancer predominantly affects male, with a sex ratio of $3: 1$, suggesting sexlinked etiological factors [6]. In the present study the male female sex ratio was 3.6: 1. In women bladder cancer usually occurs above the age of 60 years [7], in the present study however the median age was 55 years and $68 \%$ women were less than 60 years of age.

A neoplastic change in the urothelium is a multi-step phenomenon [8]. The exact genetic events leading to this multi-step transformation are unknown, but they are likely to be multiple and may involve the activation of oncogenes and inactivation or loss of tumor suppression genes [9]

Cigarette smoking is the single most important cause of bladder carcinoma. Smokers have up to four fold higher incidence of bladder cancer than do people who never smoked [10]. The risk correlates with the number of cigarettes smoked, the duration of smoking and the degree of inhalation of smoke. Causative agents in cigarette smoke are thought to be alpha and beta naphthylamine, which are secreted in to urine of smokers [11]. When compared by number of cigarettes are smoked, the risk of bladder carcinoma may be higher in women than men [12] Cigarette smoking accounts for $50 \%$ and $31 \%$ of bladder cancers in men and women respectively [13]. Other forms of tobacco use are associated with only a slightly higher risk of bladder cancer [10].

In Pakistan 36\% of men and 9\% women are smokers [14]. Tobacco is also used in other forms such as hookah (hubble bubble), moist snuff used as an oral dip (niswar), chewed with betel nuts (pan) and smoking of rolled dry leaves containing tobacco (beedi). The most common form of tobacco use in women in rural Pakistan is 
chewing tobacco and snuff but because of cultural prohibitions women may under report use of tobacco [15]. In the present study none of the women were smokers but $47 \%$ women had history of intake of moist snuff (niswar) or chewable tobacco (beera and pan) and all came from the rural areas. The median duration of use of such tobacco products was 27 years (range $10-40$ years).

Chewing tobacco and snuff contains many carcinogens. The most harmful carcinogens in smokeless tobacco are the tobacco specific nitrosamines (TSNA). They are formed during the growing, curing, fermenting and aging of tobacco [16]. Long term use of snuff can lead to a number of adverse health affects including oral cancer, cardiovascular diseases and gingival diseases [17]. However the etiological relationship between smokeless tobacco and bladder carcinoma has not been well elucidated in the literature and there is still no agreement among the researchers whether smokeless tobacco use enhances the risk of bladder cancer. Some studies reported increased risk of bladder cancer in smokeless tobacco users $[18,19]$ while others [12] could find no such risk in smokeless tobacco users. All studies included smaller number of bladder cancer patients using smokeless tobacco.

In the present study $47 \%$ women had long history of smokeless tobacco use and the correlation between the stage of bladder carcinoma and duration of smokeless tobacco was significant $(p=0.03)$. However, there was weak correlation between bladder carcinoma and intensity of exposure to smokeless tobacco. This might be due to the fact that women were using different quantities and forms of the locally available smokeless tobacco. As there is long latent period between exposure to carcinogens and the development of bladder carcinoma, it is possible that prolong use of smokeless tobacco among women in the present study was either the etiological factor or had modifying effect on its development. However further studies are required to clarify the role of smokeless tobacco in the development of bladder carcinoma.

In the USA percentage of bladder cancers attributed to occupational exposure is $21 \%$ for men and $11 \%$ for women [1]. None of the women in present study were exposed to occupational chemicals.

Majority of the patients with bladder carcinoma present with either hematuria or irritative voiding symptoms [20]. In the present study majority of women $(88 \%)$ presented with hematuria while some $(9 \%)$ had variable urinary symptoms. In one patient the tumor was incidentally detected on ultrasonography.
In the developed world transitional cell carcinoma is reported for most bladder carcinoma. About 25\% of newly diagnosed cancers are muscle invasive (T2-T4); the rest are superficial $(70 \%)$, classified as limited to the mucosa (pTa), lamina propria (pT1) or being in situ (Tis $5 \%)[21]$.

In the present study all patients had transitional cell carcinoma. Some authors have reported that bladder cancer is of a higher stage at initial diagnosis in women [1]. In the present study $25 \%$ patients had superficial (pTa/pT1) and $75 \%$ patients had muscle invasive balder carcinoma. In a report from another Pakistani centre $97 \%$ of bladder carcinomas were muscle invasive [22] but clinico-pathological differences in women with bladder cancer were not separately reported. This high percentage of muscle invasive bladder carcinoma in Pakistan is in contrast to all other studies from USA and Europe.

Overall survival in patients with superficial disease is excellent. However $60 \%-70 \%$ of superficial tumors recur and $5 \%$ of pTa and $25 \%$ of pT1 tumors progress to invasive disease [21]. For recurrence risk, multiplicity of the tumor is the most important followed by recurrence rate, volume of the tumor, grade and T category. For progression the most important factor is the histological grade and the T category T1 GIII tumors carry poor prognosis and up to $50 \%$ progress to invasive disease [23].

Patients with tumors just invading detrusor muscles have a $50 \%$ five years survival whereas those whose tumors have invaded beyond the detrusor muscle have a $10 \%$ five years. At the time of diagnosis $50 \%$ of muscle invasive tumors have occult metastases which will manifest themselves clinically within 12 months; few such patients survive beyond two years [21]. In the present study two patients had marked iliac and para-aortic lymphadenopathy while one patient had iliac and para-aortic lymphadenopathy and liver metastases at the time of diagnosis.

\section{Conclusion}

Transitional cell carcinoma is the most common bladder malignancy in women in Pakistan. Most women with bladder carcinoma have long history of use of smokeless tobacco. At the time of diagnosis $75 \%$ women have muscle invasive bladder carcinoma. In women using smokeless tobacco, there is significant correlation between stage of bladder carcinoma and duration of smokeless tobacco use. Further studies are required to clarify the role of smokeless tobacco in the development of bladder carcinoma.

\section{Acknowledgements}

The author is grateful to Professor Abrar Ahmad Javaid, Head of clinical oncology, Nishtar Medical College, Multan and Prof Hayat Awan, Dean 
Institute of management sciences, Bahauddin Zakariya University, Multan for their help during the preparation of this manuscript.

\section{References}

I. Van der Poel HG, Mungan NA, Witjes JA: Bladder cancer in women. Int Urogynecol J and pelvic floor dysfunction 1999, 10:207-2 12.

2. Lee R, Droller MJ: Natural history of bladder cancer: implications for therapy. Urol Clin North Am 2000, 27: I-I4.

3. Konety BR, Williams RD: Superficial transitional (Ta/TI/CIS) cell carcinoma of the bladder. BJU Int 2004, 94: I8-2 I

4. Jemal A, Murray T, Samuels A, Ghafoor A, Ward E, Thum M: Cancer statistics 2003. CA Cancer J Clin 2003, 53:5-26.

5. Rafique $M$, Javed AA: Role of itravenous urography and transabdominal ultrasonography in the diagnosis of bladder carcinoma. Int Braz J Urol 2004, 30: I85-190. discussion I91

6. Rabbani F, Cordon-Cardo C: Mutation of cell cycle regulators and their impact on superficial bladder cancer. Urol Clin North Am 2000, 27:83-102.

7. Baniel J: Bladder cancer in women. Int Urogennecol and pelvic floor dysfunction 1999, 10:399-404.

8. Shirai T: Etiology of bladdercancer. Semin Urol 1993, I I: I I3-126.

9. Olumi AF, Skinner EC, Tsai YC, Jones PA: Molecular analysis of human bladder cancer. Semin Urol 1990, 8:270-277.

10. Burch RD, Rohan TE, Howe CR, Risch HA, Hill GB, Steele R, Miller $A B$ : Risk of bladder cancer by source and type of tobacco exposure. Int J Caner 1989, 44:622-628.

II. Carroll PR: Urolthelial carcinoma: cancers of bladder, ureter and renal pelvis. In eds Smith General Urology I 5 th edition. Edited by: "Tanagho EA, McAninch JW". McGraw Hill publishers. USA; 2000:355-377.

12. Castelao JE, Yuan Jian-Min, Skipper PL, Tannenbaum SR, GagoDominguez M, Crowder JS, Ross RK, Yu MC: Gender and smoking related bladder cancer risk. J Nat Can Inst 200I, 93:538-545.

13. Wynder EL, Goldsmith R: The epidemiology of bladder cancer: a second look. Cancer I97I, 40:|246-I268.

14. Alam SE: Prevalence and pattern of smoking in Pakistan. J Pak Med Assoc 1998, 48:64-66.

15. PMRC National Health survey of Pakistan. Network publication services 1998.

16. Hoffmann D, Djordjevic MC: Chemical composition and carcinogenicity of smokeless tobacco. Adv Dent Res 1997, I I:322-329.

17. Fant RV, Henningfield JE, Nelson RA, Pickworth WB: Pharmacokinetics and pharmacodynamics of moist snuff in humans. Tob Control 1999, 8:387-392.

18. Slattery ML, Schumacher MC, West DW, Robinson LM: Smoking and bladder cancer. The modifying effect of cigarettes on other factors. Cancer 1998, 6 I:402-408.

19. Kabat GC, Dieck GS, Wynder EL: Bladder cancer in non smokers. Cancer 1986, 57:362-367.

20. Carrion Rafael, Seigne J: Surgical management of bladder carcinoma. Cancer Control 2002, 9:284-292.

21. Leung HY, Griffiths TRI, Neal DE: Bladder cancer. Post Grad Med J 1996, 72:719-724.

22. Roohullah, Nusrat J, Hamadani SR, Burdy GM, Khurshid A: Carcinoma urinary bladder: 5 years experience at Cenar, Quetta. J Ayyub Med Coll Abottabad 2001, I3:14-16.

23. Oosterlinck W: Guidelines on diagnosis and treatment of superficial bladder cancer. Minerva Urol Nefrol 2004, 56:65-72.

\section{Publish with Biomed Central and every scientist can read your work free of charge}

"BioMed Central will be the most significant development for disseminating the results of biomedical research in our lifetime. "

Sir Paul Nurse, Cancer Research UK

Your research papers will be:

- available free of charge to the entire biomedical community

- peer reviewed and published immediately upon acceptance

- cited in PubMed and archived on PubMed Central

- yours - you keep the copyright

Submit your manuscript here:

http://www.biomedcentral.com/info/publishing_adv.asp
BioMedcentral 